\title{
A review of decision-making models in end-of-life care in Singapore
}

\author{
Jann Adriel Sy ${ }^{1}$, Mark MJ Tan ${ }^{1}$ and Lalit Kumar Radha Krishna ${ }^{1-4}$ \\ ${ }^{1}$ Duke-NUS Graduate Medical School, Class of 2017, Singapore \\ ${ }^{2}$ Yong Loo Lin School of Medicine, National University of Singapore, Singapore \\ ${ }^{3}$ Lien Centre for Palliative Care, Duke-NUS Graduate Medical School, Singapore \\ ${ }^{4}$ Division of Palliative Medicine, National Cancer Centre, Singapore
}

\begin{abstract}
End of life decision-making for incompetent patients should be guided by the Best Interests Principle (BIP); however, emerging utilization of other decision-making tools such as individual autonomy, relational autonomy and welfare-based models have led to widely dissimilar conclusions being drawn.

We argue that these variances occur not as a result of misapplication of these decision-making models but rather as a result of misinterpretation of the manner that these tools are utilized within the local setting. We believe that individual autonomy, relational autonomy, BIP and welfare-based models have their place in the decision-making process. We suggest that rather than being discrete decision-making models, these tools ought to be taken as part of a decision-making spectrum. We forward provisions that allow for the selection of the appropriate decision-making models to suit patient-specific considerations and discuss application of the models in Advance Care Planning (ACP), At-Own-Risk (AOR) discharges and Palliative Sedation (PS).
\end{abstract}

\section{Introduction}

Care determinations for incompetent terminally ill patients are traditionally guided by the Best Interests Principle (BIP), yet the presence of complex sociocultural considerations within the Singapore end of life care setting has seen the employ of a number of other decisionmaking models locally [1-7]. These situations arise in response to the failure of atomistic Western ethical concepts to contend with family centric values that continue to dominate the local ethical, cultural and social landscape $[4,8]$.

Attempts to address the apparent dichotomy of a family centric approach with atomistic centered Western ethical concepts have seen divergent solutions being relied upon. On one end, attempts have been made to marry the two dominant ethical approaches through the provision of the Relational Autonomy model, which sees attention shift from the individual to the interests of the individual and their family. At the other extreme, there have been attempts to shift attention from the largely Western concept of autonomy-based decision making to a beneficence-driven paternalistic Welfare Model. Applications of these concepts either on their own or in tandem with the BIP ultimately to safeguard the best interests of the patient have unsurprisingly led to divergent care outcomes and to poor experiences with palliative care teams for many families [9].

Devising an appropriate means of choosing the appropriate approach to be adopted in care determinations has become increasingly important. While such a solution remains some way off, provision of a better understanding of the various concepts available may be an appropriate starting point.

For clarity, this discussion will take place within Singapore's Confucian-based family centric society where filial piety or familial obligations to the elder and vulnerable family members dominate sociocultural thinking and even influence legal precepts [10,11]. Local care provisions, especially in end of life decision making, continue to emphasize the primacy of the family in care determinations, whilst local statutes such as the Singapore's Maintenance of Parents Act 1996 continue to recognize the filial duties of the family to their parents [12]. Indeed, family-centric beliefs are cemented within Singapore's national ideology and community values, and they continue to define governmental initiatives, such as efforts by the Ministry of Social and Family development to promote filial piety amongst Singaporeans [13].

Increasingly, however, tensions appear to have arisen in the local ranks, with data suggesting that an increasing number of patients view themselves as atomistic individuals, raising tensions in care determinations [14]. In view of all these, closer scrutiny of prevailing individual autonomy, relational autonomy, BIP and welfare-based models are called for.

\section{Current decision making models used in end-of-life care}

\section{Individual autonomy and Relational autonomy}

Respect for Autonomy has sometimes been referred to as "the first amongst equals" to highlight its centrality within the four principles of medical ethics $[15,16]$. The essence is to respect a patient's choices made without interference from external forces. It underpins the practices of confidentiality and veracity - confidentiality in that the promise of privacy enables the patient to make autonomous decisions free of

Correspondence to: Mark Tan Min Jian, Duke-NUS Graduate Medical School, Class of 2017, Singapore, Tel: +65 9106 2104; E-mail: markmj@u.duke.nus.edu

Received: July 05, 2015; Accepted: August 22, 2015; Published: August 25, 2015 
interference, and veracity in that the patient makes proper decisions on the basis of truth and medical facts.

Ideally, where a patient has made clear his or her wishes and the family respects these wishes, respect for individual autonomy is clearcut. However, atomistic conceptions of autonomy are only applicable if the patient has been willing or, more pertinently, allowed to engage in discussions end-of-life care and it assumes that the patient maintains capacity in making medical decisions. In the context of a familycentric society, such as in Singapore, where family is seen as the core societal unit rather than the individual, it is the family that frequently determines the course of care. For example, poor health and limiting illness are sometimes seen as socially taboo and augur poor outcomes, this may encourage family centric practices of collusion, familial determination and circumnavigation of direct patient involvement with the intent to maintain hope in the patient, which is seen by some as the lifeblood of longevity [9]. The cumulative effect of family centric practices and prevailing sociocultural effects leave patients with compromised decision-making capacities and the inability to participate in the shaping of their own care.

Unsurprisingly, local physicians are frequently 'forced' to speak to the primary caregiver, who is usually one of the children, and discuss the management of the patient, since it is the patient's son or daughter who will bear the burden of care [9]. There are also instances where family members of the patient collude with physicians in order to prevent the patient from knowing the diagnosis to spare them grief [5]. The culmination of these practices, beliefs and social norms that still dominate local care provisions leaves respect for individual autonomy severely compromised.

To accommodate these regnant beliefs and values, a wider concept of the principle of autonomy was proposed. Relational Autonomy (RA) adopts an inclusive view of family involvement in care determinations and sees the patient and family as an intimately entwined unit. Here, the family's role and position in keeping with local sociocultural beliefs is acknowledged and conferred a significant role within the decision making process.

However, growing concern about the ability of the family to dissociate their interests from those of the family and to act to advance the wellbeing of the patient has led to the discrediting of the RA approach. Competing interests arise for a number of reasons. Firstly, Singapore's shared healthcare financing, which see healthcare costs shared between the government and patients and their family results in the family effectively shouldering the burden of treatment, creating, not uncommonly, conflicts of interests. Secondly, continued reliance upon the family as primary providers of physical, social, financial, psychological and spiritual support is a significant consideration, particularly when such responsibilities come at no small personal cost to family members.

Likewise, local families do continue to maintain strong filial values reinforced by social and familial expectations. This sees families keen to meet their filial obligations to care and support their loved ones, to meet their duty of non-abandonment of the patient, and to maintain hope despite the patient's dire outlook. In fact, there have been many local accounts of families choosing to pursue aggressive, non-conventional and even potentially harmful treatment options simply to meet these duties [5].

The culmination of these considerations and the continued pressure upon the patient sustains the growing concern on the ability of the family to act in a manner that will protect the patient's quality of life within a palliative intent, and ultimately leads the authors to challenge the use of the RA approach in such situations.

\section{Best interest principle and welfare-based model}

Search for a viable decision-making approach has then turned the attention of some practitioners to the use of a team-based application of the BIP, which dictates that for a person lacking capacity, decisions with regards to their care should be taken in their best interests and must take into account of the patient's past and present wishes, beliefs and values, as well the views of others engaged in the patient's care, to the best of the primary physician's knowledge [7]. Here, however, the views of the family are not with the prerogative it has enjoined in prevailing conceptions, but rather as one of the many factors considered. Yet, concerns arise as to the accuracy and balance of such determinations taken almost exclusively upon by the assessment of the primary physician, causing dissatisfaction among caregivers and raising questions as to the accountability and the nature of the decisions made have been raised.

The Welfare Model (WM) introduces the idea of replacing the primary physician in assessing and determining the coarse of action for a particular patient with a multidisciplinary palliative team (MDT) to confer greater accountability and transparency to the decision making process $[3,4]$. Focused upon maintaining the patient's overall welfare as determined by the MDT, the WM is primarily beneficence driven. The apparent return to medical paternalism however has raised disquiet amongst clinicians.

Whilst there are significant concerns about prevailing decisionmaking models, we believe that each has a role within the diverse Singaporean society.

\section{Discussion}

While each of these decision-making models have been viewed as discrete entities, from a practical standpoint, scrutiny of the degree of individual involvement and family involvement, the extent that multiple views are considered and with whom the final decisionmaking authority rests suggests that these models actually lie along a decision-making spectrum with the paternalistic WM lying at one end and the Individual Autonomy model at the other. Summary of this analysis is provided in Table 1.

Based on this analysis, we propose a set of general guidelines for selecting decision-making tools:

i. Individual Autonomy should be respected wherever possible unless there are sufficient grounds to dispute the individual's decisionmaking capacity

ii. Family input should be involved in RA, WM and Individual autonomy models if requested by the patient.

iii. In situations where the family is the primary providers of care and support, and alternatives are lacking, a RA model may be appropriate and we believe that the rights of care providers should be taken into consideration. Critically, when the family's agreement is essential to the provision of care and future treatment plans after discharge, an RA model remains the most viable decision-making model.

iv. WM takes center stage if the decisions made using other models run contrary to the preservation of the patient's overall welfare. 
Table 1. Analysis of the 4 key elements of the decision-making models.

\begin{tabular}{|c|c|c|c|c|}
\hline Decision making models & Individual Autonomy & $\begin{array}{c}\text { Relational Autonomy } \\
\text { (RA) }\end{array}$ & Best Interests Principle (BIP) & Welfare-based model (WM) \\
\hline Individual involvement & $\begin{array}{l}\text { High, } \\
\text { Capacity to make decisions }\end{array}$ & Low-Moderate & Tempered & Tempered with greater patient centeredness \\
\hline Family involvement & Low & High & Tempered & Tempered \\
\hline Multidimensional input & Patient - physician & Family conference & $\begin{array}{l}\text { Family conference, palliative } \\
\text { team }\end{array}$ & $\begin{array}{l}\text { Family conference, multiple disciplinary input. Bias } \\
\text { tempered by palliative team }\end{array}$ \\
\hline Final decision making & Patient & $\begin{array}{l}\text { Patient with family } \\
\text { influence or Family }\end{array}$ & Primary care team & $\begin{array}{c}\text { Based on all MDT inputs, coordinated by Palliative } \\
\text { team }\end{array}$ \\
\hline Medical paternalism & Low & Low & High & High \\
\hline
\end{tabular}

Employ of the WM is reserved to situations where concerns exist about the patient's best interests.

v. When applied, decisions taken by the WM need to be documented, justified and evidenced-based and wherever possible reviewed by an independent palliative care specialist.

To understand the implementation in typical clinical settings, we shall consider these decision-making tools in the (1) employ of Advanced Care Planning (ACP) where the patient sets out clear guidance upon the direction of care they envisage for themselves when they themselves are no longer capable of making such decisions, (2) "At own risk" (AOR) discharges within the palliative care setting where there are potential for serious repercussions upon the welfare and life expectancy of the patient, and (3) applications of Palliative Sedation (PS) or deep continuous sedation to induce a state of sustained unconsciousness to negate awareness of intractable suffering at the end of life which commonly involve patients whose ability to consent is compromised as a result of their symptoms.

\section{i. $\mathrm{ACP}$}

For many local patients, the presence of taboos on participating in end of life discussions and the continued employ of family centric practices inhibit effective decision-making on end of life care [1722]. While such concerns are prevalent, it is also clear that there are exceptions to this, particularly within the younger patient population. Denying the chance to establish personal choice and goals of care would denigrate the process of care planning. Rather than generalizing practice decisions, viability of ACPs should be considered on a caseby-case basis.

In respect of individual autonomy, ACPs assessed to be made without external pressures and in light of full disclosure of the facts should be respected. In cases where there is concern that care considerations are confronted by situations that the patient could not have foreseen, such as events not within the scope of the ACP, a RA approach ought to be used in the first instance. Otherwise, validity of decisions should be assessed using the WM.

Alternatively, it may also be entirely appropriate that the initial application of the ACP considers the wishes and input of the family if that is the specific wish of the patient. Equally, the presence of previously stated and verifiable wishes by the patient that specific members of the family be decision makers should be given credence so long as the decisions made do not run contrary to the best interests of the patient.

ii. "At own risk" (AOR) discharges within the palliative care
setting

AOR discharges occur in most clinical settings and are generally respected and represent the termination of the therapeutic relationship between a patient and a physician. Concern arises when patients requesting such discharges do so either under duress or without true insight into their condition $[9,12,22,23]$.

Careful discussion with the patient is pivotal, and should cover, as appropriate, a multidimensional review of their condition and the potential pitfalls of their decisions. In a nation that places great value on preserving life, as exemplified by its proscription of support for suicide and implementation of acts that prevent the employ of euthanasia and physician assisted suicide (PAS/E), the potential for abbreviation in life or significant compromise of patient welfare cannot be ignored.

The use of an MDT approach may be appropriate to fully assess the situation, yet this does not mean that AOR discharges should never be permitted. Rather it suggests that all effort be made to ensure that there is valid and effective support of the patient upon their discharge. For example, in a relatively young independent patient who is mentally well and judged to have capacity in pursuing an AOR discharge, respect for individual autonomy is best used. Meanwhile, in an elderly unwell patient who is under duress by family to make a decision quickly and are pressuring him to AOR discharge, the WM may be necessary to explore the reasons for AOR discharge, and resolve the situation in the best interest of the patient.

\section{iii. Application of Palliative Sedation (PS)}

There are situations in which patients at the end of life endure intractable suffering not amenable to standard treatment. In many of these cases, the patients are unable to provide informed consent for the employ of PS, the treatment of last resort for patients with a prognosis of less than two weeks and in whom all other forms of standard treatment has failed to effectively alleviate symptoms [24-27].

Balance between patient welfare, their previous goals of care, values and beliefs and the wishes of the family is sought in making a decision for PS [28]. While it has been argued that PS ought to be applied as a matter of a patient's best interests, in light of its relative safety and the prospect of continued suffering until death, provisions must be made to consider the views of the family and any decision must be weighed upon the results of a multidisciplinary multidimensional review of the case. A RA model may be appropriate if there is no suspicion of willful compromise to the patient's welfare. Potentially, the combination of a RA and WM may be the most beneficial, yet the selection of this decision-making process must be case specific and context sensitive.

\section{Considerations in employing the WM model}

While it may be tempting to escalate care towards a WM, its application is relatively resource-dependent, with the limitation that 
assembling the MDT is subject to manpower and time constraints. The possibility of oversights within the MDT decision making process should also be addressed with internal and external auditing for consistency and integrity of workflow. These considerations would ultimately limit the number of cases that may employ the WM. A key undertaking for the future may be to develop inclusion and exclusion criteria for the employ of the MDT for clarity while remaining flexible enough to deal with the contextual variability of end of life care.

\section{Conclusion}

The recent examples cited in our paper illustrates that there is little consistency in the management of end-of-life issues currently in Singapore and it is critical to recognize that the dynamics of each case vary extensively depending on the patient, family, prognosis and medical care teams. Hence, choosing a suitable existing decision making model may in itself cause confusion and hinder efficiency in implementation for the individual's best interests.

The theoretical spectrum merely provides a new perspective to an age-old issue that still requires a more detailed framework to be elucidated. Future work should detail more standardized protocols and pathways within each model and guidelines on indications to escalate to more paternalistic models.

\section{References}

1. Mohanti BK (2009) Ethics in palliative care. Indian J Palliat Care 15: 89-92. [Crossref]

2. Krishna LKR(2011) Decision making at the end of life: A Singaporean Perspective. Asian Bioethics Review 3: 118-126.

3. Krishna LR (2012) Best interests determination within the Singapore context. Nurs Ethics 19: 787-799. [Crossref]

4. Krishna LK, Watkinson DS, Beng NL (2015) Limits to relational autonomy--the Singaporean experience. Nurs Ethics 22: 331-340. [Crossref]

5. Ho ZJ, Radha Krishna LK, Yee CP (2010) Chinese familial tradition and Western influence: a case study in Singapore on decision making at the end of life. $J$ Pain Symptom Manage 40: 932-937. [Crossref]

6. Mental Capacity Act 2005. (c.9). London: HMSO.

7. Mental Capacity Act 2008. (c.177A). Singapore: AGC.

8. Wilson F, Ingleton C, Gott M, Gardiner C (2014) Autonomy and choice in palliative care: time for a new model? J Adv Nurs 70: 1020-1029. [Crossref]

9. Krishna LKR, Menon S (2014) Understanding the Practice of Collusion on End of Life Care in Singapore. JMED Research.
10. Cheng CY (1986) The Concept of face and its Confucian Roots. Journal of Chinese Philosophy 13: 329-348.

11. Tsai DF (2001) How should doctors approach patients? A Confucian reflection on personhood. J Med Ethics 27: 44-50. [Crossref]

12. Maintenance of Parents Act 1996. (c.167B). Singapore: AGC.

13. Toh HC (2011) Providing hope in terminal cancer: when is it appropriate and when is it not? Ann Acad Med Singapore 40: 50-55. [Crossref]

14. Yap WQ(2010) Filial piety commercial receives good comments. Shin Min Daily News Jun 26

15. Gillon R (1994) Medical ethics: four principles plus attention to scope. BMJ 309: 184 188. [Crossref]

16. Gillon R (2003) Ethics needs principles--four can encompass the rest--and respect for autonomy should be "first among equals". J Med Ethics 29: 307-312. [Crossref]

17. Fried TR, O'Leary J, Van Ness P, Fraenkel L (2007) Inconsistency over time in the preferences of older persons with advanced illness for life-sustaining treatment. $J \mathrm{Am}$ Geriatr Soc 55: 1007-1014. [Crossref]

18. Fried TR, Van Ness PH, Byers AL, Towle VR, O'Leary JR, et al. (2007) Changes in preferences for life-sustaining treatment among older persons with advanced illness. $J$ Gen Intern Med 22: 495-501. [Crossref]

19. Lien Centre for Palliative Care, Duke-NUS Graduate Medical School [Internet] (2011) Report on the National Strategy for Palliative Care. Available from: https://www.dukenus.edu.sg/news/report-national-strategy-palliative-care

20. Ng R, Chan S, Ng TW, Chiam AL, Lim S (2013) An exploratory study of the knowledge, attitudes and perceptions of advance care planning in family caregivers of patients with advanced illness in Singapore. BMJ Support Palliat Care 3: 343-348. [Crossref]

21. Yee A, Seow YY, Tan SH, Goh C, Qu L, et al. (2011) What do renal health-care professionals in Singapore think of advance care planning for patients with end-stage renal disease? Nephrology (Carlton) 16: 232-238. [Crossref]

22. Advanced Medical Directive Act 1997. (c.4A). Singapore: AGC.

23. Medical and Elderly Care Endowment Schemes Act 2000. (c.173A). Singapore: AGC.

24. Krishna L (2010) Consent in terminal sedation. Indian J Med Ethics 7: 161-164 [Crossref]

25. Krishna LKR, Ho S (2015) Reapplying the "Argument of Preferable Alternative" within the Context of Physician-Assisted Suicide and Palliative Sedation. Asian Bioethics Review 7: 62-80.

26. Krishna L (2011) The Position of the Family of Palliative Care patients within the Decision Making Process at the end of life in Singapore. Ethics and Medicine 27: 183190.

27. Krishna L, Chin J (2011) Terminal Sedation within the Duty of Palliative Care. Asian Bioethics Review 3: 201-215.

28. Krishna LR (2012) Best interests determination within the Singapore context. Nurs Ethics 19: 787-799. [Crossref]

Copyright: (C2015 Sy JA. This is an open-access article distributed under the terms of the Creative Commons Attribution License, which permits unrestricted use, distribution, and reproduction in any medium, provided the original author and source are credited. 